\title{
Evaluating Source Area Contributions from Aircraft Flux Measurements Over Heterogeneous Land Using Large-Eddy Simulation
}

\author{
Giacomo Bertoldi • William P. Kustas • \\ John D. Albertson
}

Received: 15 December 2011 / Accepted: 24 October 2012 / Published online: 15 December 2012

C Springer Science+Business Media Dordrecht 2012

\begin{abstract}
The estimation of spatial patterns in surface fluxes from aircraft observations poses several challenges in the presence of heterogeneous land cover. In particular, the effects of turbulence on scalar transport and the different behaviour of passive (e.g. water vapour) versus active (e.g. temperature) scalars may lead to large uncertainties in the source area/fluxfootprint estimation for sensible $(H)$ and latent $(L E)$ heat-flux fields. This study uses largeeddy simulation (LES) of the land-atmosphere interactions to investigate the atmospheric boundary-layer (ABL) processes that are likely to create differences in airborne-estimated $H$ and $L E$ footprints. We focus on $32 \mathrm{~m}$ altitude aircraft flux observations collected over a study site in central Oklahoma during the Southern Great Plains experiment in 1997 (SGP97). Comparison between the aircraft data and traditional model estimates provide evidence of a difference in source area for turbulent sensible and latent heat fluxes. The LES produces reasonable representations of the observed fluxes, and hence provides credible evidence and explanation of the observed differences in the $H$ and $L E$ footprints. Those differences can be quantified by analyzing the change in the sign of the spatial correlation of the $H$ and $L E$ fields provided by the LES model as a function of height. Dry patterns in relatively moist surroundings are able to generate strong, but localized, sensible heating. However, whereas $H$ at the aircraft altitude is still in phase with the surface, $L E$ presents a more complicated connection to the surface as the dry updrafts force a convergence of the surrounding moist air. Both the observational and LES model evidence support the concept that under strongly advective conditions, $H$ and $L E$ measured at the top of the surface layer $(\approx 50 \mathrm{~m})$ can be associated with very different upwind source areas, effectively contradicting surface-layer
\end{abstract}

G. Bertoldi ( $\varangle)$ · J. D. Albertson

Department of Civil and Environmental Engineering, Duke University, Durham, NC, USA

e-mail: giacomo.bertoldi@eurac.edu

Present Address:

G. Bertoldi

Institute for Alpine Environment, EURAC Research, Viale Druso1, 39100 Bolzano, Italy

W. P. Kustas

USDA-ARS Hydrology and Remote Sensing Laboratory, Beltsville, MD, USA 
self-similarity theory for scalars. The results indicate that, under certain environmental conditions, footprint models will need to predict differing source area/footprint contributions between active $(H)$ and passive $(L E)$ scalar fluxes by considering land-surface heterogeneity and ABL dynamics.

Keywords Aircraft flux measurements - Flux footprint · Land-surface fluxes · Large-eddy simulation $\cdot$ Surface heterogeneity

\section{Introduction}

Spatially distributed land-surface fluxes, estimated by land-surface models and/or remote sensing observations, are often validated using tower or airborne flux measurements. To properly compare modelled and measured fluxes, one must estimate the upwind source area/fluxfootprint of the measurements in order to determine the appropriate contributing model grid cells and/or pixels that must be aggregated to the measurement scale and position.

Both Lagrangian (i.e. Leclerc and Thurtell 1990; Fleisch 1996; Hsieh et al. 2000; Kljun et al. 2002; Cai and Leclerc 2007) and Eulerian (i.e. Schuepp et al. 1990; Horst and Weil 1992) footprint models assume horizontally uniform profiles of the mean horizontal wind speed $U(z)$, and of the variance of vertical velocity $\sigma_{\mathrm{w}}^{2}$ (Schmid 2002). However, over heterogeneous landscapes with strong contrasts in surface soil moisture and vegetation cover this assumption is typically violated (Kelly et al. 1992; Kaharabata et al. 1997; Kustas et al. 2006; LeMone et al. 2007). In fact, over heterogeneous terrain with inhomogeneous surface heating, measurements indicate that $U(z), \sigma_{\mathrm{w}}^{2}$, and also the scalar variances have strong spatial variability (LeMone et al. 2003). The vertical velocity fluctuations tend to be of a higher magnitude over the arid patches, resulting in localized maxima in turbulent scalar fluxes (e.g., Lenschow et al. 1980; Young 1988).

This heterogeneity may indicate that the relationship between sensible $(H)$ and latent $(L E)$ heat fluxes changes with altitude. Using tower and aircraft flux measurements LeMone et al. (2003) found that the $H-L E$ correlation (defined here as $\rho(H, L E)$ ) changes from negative at about $2 \mathrm{~m}$ to positive at about $30 \mathrm{~m}$ above local terrain. LeMone et al. (2003) suggested that this behaviour in $H$ and $L E$ may be due to a confluence of these fluxes in the boundary-layer scale updrafts, resulting in a positive $\rho(H, L E)$ above a certain altitude, while, near the surface, the turbulent fluxes are constrained by the local surface energy balance and, therefore, $H$ and $L E$ exhibit a negative correlation.

Other studies suggest that a progressive decoupling with increasing altitude of airborne surface fluxes from the surface features is related to the different behaviour of passive (water vapour) versus active (temperature) scalar fluxes (e.g. Roth and Oke 1995; Sempreviva and Hojstrup 1998; Asanuma and Brutsaert 1999). Albertson and Parlange (1999a), using largeeddy simulation (LES) for an artificial patchwork of fields, showed that water vapour appeared to be carried more nearly horizontally over wet fields and ultimately carried upward in thermally driven eddies over downwind arid regions, while sensible heat was immediately convected upward in buoyant plumes above local sensible heat sources.

Over heterogeneous landscapes $H$ and $L E$ usually have different source regions, since dry patches (low $L E$ ) generally correspond to higher surface heating (high $H$ ) and vice versa (Kustas and Albertson 2003). Therefore, the increase in both $H$ and $L E$ in updrafts requires different footprint estimates for $H$ and $L E$ (Kustas et al. 2006). Ignoring this difference leads to greater uncertainty in relating spatial patterns of fluxes from aircraft observations to underlying landscape features (Kaharabata et al. 1997, 1999). 
Large-eddy simulation has been shown to be a powerful approach for simulating complex footprint conditions over heterogeneous surfaces (e.g. Leclerc et al. 1997; Huang and Margulis 2009). However, there is still a need to move beyond LES applications with synthetic surfaces/conditions and apply LES to real landscapes and address problems of horizontal inhomogeneity in realistic flow fields (Schmid 2002; Huang et al. 2011; Garcia-Carreras et al. 2011).

In the present study, LES is conducted for a real heterogeneous landscape in order to gain a more fundamental understanding of the physical factors and turbulent processes that cause different source-area/flux-footprint requirements for $H$ and $L E$. The focus is on lowaltitude $(\approx 30 \mathrm{~m})$ aircraft-based flux observations (Mahrt et al. 2001) collected during the 1997 Southern Great Plains (SGP97) experiment (Jackson et al. 1999). Kustas et al. (2006) analyzed aircraft and model-based surface fluxes and found that a much smaller flux-footprint was required for $H$ to achieve maximum agreement with aircraft-based flux observations, as compared to that for $L E$. Moreover, aircraft observations showed a strong localized increase in $H$ over hot, dry, and bare field patches, while no corresponding localized decrease was observed in the aircraft-measured $L E$. The physical mechanisms contributing to different transport processes for heat and water vapour could not be resolved with these observations; hence, LES with the actual surface boundary conditions from remote sensing-based observations are used here to evaluate the numerical evidence of different transport of $H$ and $L E$. The analysis includes considering the spatial correlations of the turbulent fluxes as a function of altitude and the spatial structure of the variances of the scalar fields and of the vertical velocity.

The specific objectives of this paper are to: (i) verify the ability of LES to simulate observed aircraft-based $H$ and $L E$ patterns; (ii) determine key mechanisms that contribute to the observed changes in $H$ and $L E$ spatial patterns from the aircraft flux measurements over such a heterogeneous landscape; and, (iii) examine the implications resulting from dissimilarity in $H$ and $L E$ footprint behaviour.

\section{Data and Methods}

The remote sensing and hydrometeorological observations used in this study are taken from the Southern Great Plains Experiment of 1997 (SGP97). Details of the SGP97 experimental design are described by Jackson et al. (1999) and also at:http://hydrolab.arsusda.gov/sgp97/.

Our study focuses on data collected on July 2, 1997 over a $38 \mathrm{~km}^{2}$ region surrounding the USDA-ARS Grazing Lands Research Facility near El Reno, Oklahoma, USA, which is mainly comprised of plowed wheat, stubble/bare soil or harvested winter wheat and rangeland/pasture used for grazing. A detailed description of this area can be found in Kustas et al. (2006). On July 2, 1997 there was a large contrast in surface temperature, canopy cover, and roughness between relatively cool vegetated areas with near-potential transpiration and dry bare soil areas with high surface temperature and large sensible heating, as shown in Fig. 1a. Of particular interest are the effects on the aircraft-derived fluxes from the hot, dry, bare fields indicated with the letters "A" and "B" in Fig. 1a, located just north of the aircraft transect track, having a $20 \mathrm{~K}$ difference in radiometric surface temperature $T_{\mathrm{s}}$ with the surrounding well-watered vegetated fields.

\subsection{Field Measurements}

Aircraft flux and atmospheric boundary-layer (ABL) profiling observations were made by the National Research Council (NRC) of Canada using a Twin Otter atmospheric research 


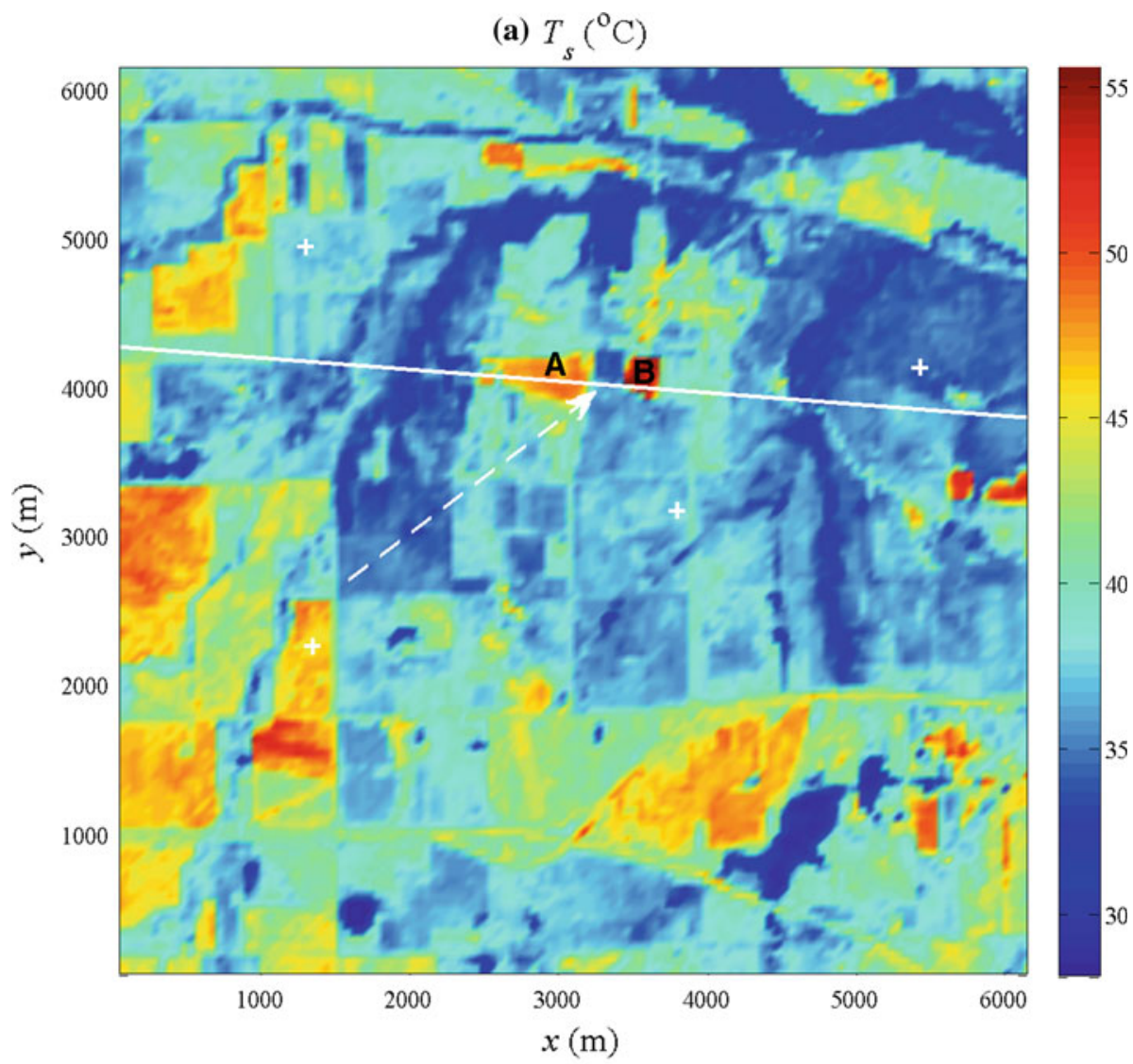

(b) Aircraft $H$ and $L E$ values ( $\mathrm{W} \mathrm{m}^{-2}$ ) - 1030 CST overpass

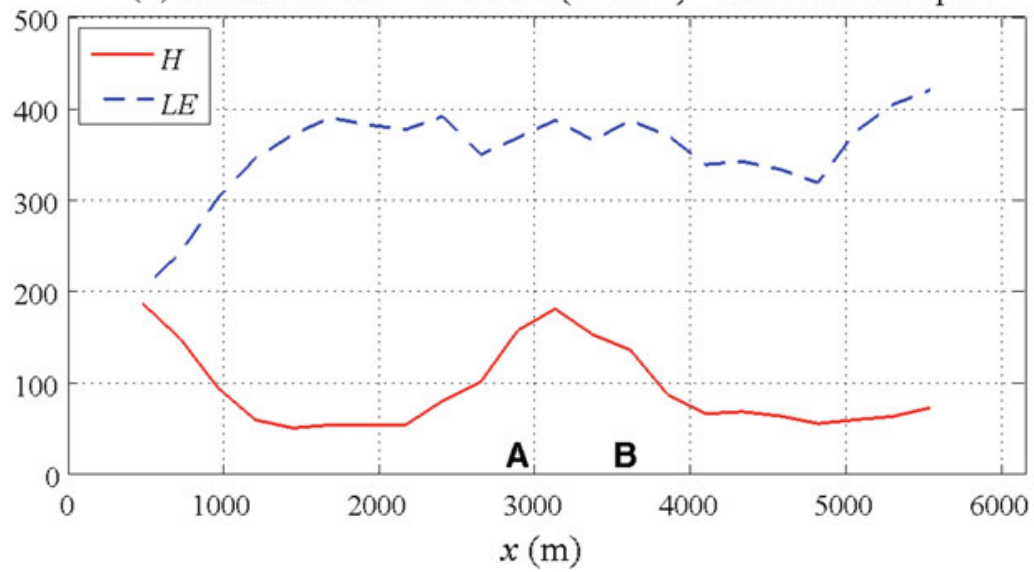

Fig. 1 a Upper panel spatial distribution of radiometric surface temperature $\left(T_{\mathrm{S}},{ }^{\circ} \mathrm{C}\right)$ over the study site for July 2, 1997 at 1020 CST. The aircraft flight track (continuous line), the main wind direction (dashed arrow), and flux-tower locations (plus sign) are indicated. The letters " $A$ " and " $B$ " indicate the hot, dry fields discussed in the text. b Lower panel spatial variations in aircraft-estimated $H$ and $L E$ along the aircraft overpass at 1018 CST 
aircraft within the SGP97 study area. Data processing and preliminary flux estimates for the run-averaged data for each flux transect are provided by MacPherson (1998). A single flight track, $15 \mathrm{~km}$ in length (the section of the flight track inside the LES domain is indicated in Fig. 1a), was flown over the El Reno site, with the aircraft flying 12 times from 0950 to 1225 Central Standard Time (CST) at approximately $32 \mathrm{~m}$ above local ground altitude. From data collected over the full transect, Mahrt et al. (2001) computed segmented flux values over $1 \mathrm{~km}$ intervals, which they then sub-sampled over a $250 \mathrm{~m}$ moving window. For estimating the surface fluxes in space and time, he used a filter based on a horizontal blending length scale of $1 \mathrm{~km}$. For the type of land-surface variability observed in SGP97, a 1-km averaging length was determined to be the optimal compromise between sampling requirements and resolving the spatial heterogeneity. The resulting $H$ and $L E$ patterns are illustrated in Fig. $1 \mathrm{~b}$.

Radiometric surface temperature, $T_{\mathrm{s}}$, normalized difference vegetation index (NDVI), and vegetation cover fraction $\left(f_{\mathrm{c}}\right)$ maps were derived from measurements made with the Thermal Infrared Multi-spectral Scanner (TIMS) and the Thematic Mapper Simulator (TMS), flown by aircraft over the El Reno site. The land cover and $f_{\mathrm{c}}$ maps were then used to derive the aerodynamic surface roughness properties. See French et al. (2003) for further details concerning the processing of these data. In addition to aircraft observations, vertical soundings of temperature and water vapour were sampled several times over the day and tower flux measurements were collected at four locations (crosses indicated in Fig. 1a) within the El Reno study area using the eddy-covariance technique (Twine et al. 2000).

Kustas et al. (2006) compared the aircraft-based fluxes with results from the remote sensing-based Two-Source Energy Balance (TSEB) model (Norman et al. 1995; Kustas and Norman 1999). They used the footprint model of Schuepp et al. (1990) to estimate the source area for heat and water vapour, and found that the optimal model-measurement agreement required the use of different upwind source areas (i.e. flux footprints) for $H$ and $L E$. Using the mean wind speed $U$ between the surface and the aircraft altitude and the friction velocity $u_{*}$ averaged along the aircraft path, the estimated maximum contribution of the standard footprint function was predicted to be approximately $250 \mathrm{~m}$ south-west of the transect. However, when the footprint model was calibrated to maximize the correlation between modelled and measured $H$ and $L E$, the estimated source area for $H$ was $\approx 70 \mathrm{~m}$ downstream and for LE was $\approx 150 \mathrm{~m}$.

Locations at the surface having low $f_{\mathrm{c}}$ and high $T_{\mathrm{s}}$ generally corresponded to high $H$ and low $L E$ along the aircraft track. However, this did not occur for two localized areas below the flight track (e.g. areas A and B in Fig. 1), where a strong increase in $T_{\mathrm{S}}$ and a decrease in $f_{\mathrm{c}}$ produced an increase in $H$ along the aircraft track, but no corresponding decrease in $L E$. This is evident also in the high frequency $(30 \mathrm{~Hz})$ aircraft measurements (not shown here), where a strong localized increase in spatial variance of the potential temperature $\theta$ and of the vertical velocity $w$ persisted for multiple passes along the flight track, indicative of thermals or buoyant plumes (Lenschow 1970). However, there was not a similar pattern observed in the variance of the specific humidity $q$.

\subsection{The LES Model and Simulation Settings}

The ABL evolution over the study region is simulated here using a LES model that is based on Albertson (1996), coupled with the land surface through the TSEB model (Norman et al. 1995; Kustas and Norman 1999) that uses remotely-sensed surface boundary conditions, primarily $T_{\mathrm{s}}$ and $f_{\mathrm{c}}$, as input. This combined LES — remote sensing modelling system provides a dynamic coupling between land surface and the lower atmosphere. The boundarylayer parametrization and the numerical details of the LES code are described elsewhere 
Table 1 Simulation settings and spatially- and time- averaged atmospheric properties

\begin{tabular}{ll}
\hline Temporal average duration & $1 \mathrm{~h}$ from 0945 CST to 1045 CST \\
Grid mesh $(x, y, z)$ & $128 \times 128 \times 171$ nodes \\
Grid resolution $(x, y, z)$ & $48 \mathrm{~m} \times 48 \mathrm{~m} \times 5 \mathrm{~m}$ \\
Domain dimension $(x, y, z)$ & $6,144 \mathrm{~m} \times 6,144 \mathrm{~m} \times 850 \mathrm{~m}$ \\
Inversion height $Z_{i}$ & From $450 \mathrm{~m}$ at $0945 \mathrm{CST}$ up to $650 \mathrm{~m}$ \\
Lapse rate & at $1045 \mathrm{CST}$ \\
Net radiation $R_{\mathrm{SW}}$ & $822 \mathrm{~K} \mathrm{~km}^{-1}$ \\
Surface temperature $T_{\mathrm{S}}$ & $38.7^{\circ} \mathrm{C}^{-2}$ \\
Air temperature at $2.5 \mathrm{~m} T_{\mathrm{a}}$ & $30.8^{\circ} \mathrm{C}$ \\
Specific humidity at $2.5 \mathrm{~m} q$ & $17.9 \mathrm{~g} \mathrm{~kg}^{-1}$ \\
Wind speed at $2.5 \mathrm{~m} U$ & $3.3 \mathrm{~m} \mathrm{~s}^{-1}$ \\
Wind direction at $2.5 \mathrm{~m} \alpha$ & $231^{\circ}$ \\
Wind speed at $32 \mathrm{~m} U_{\mathrm{t}}$ & $5.0 \mathrm{~m} \mathrm{~s}^{-1}$ \\
Friction velocity $u_{*}$ & $0.38 \mathrm{~m} \mathrm{~s}^{-1}$ \\
Obukhov length $L_{\mathrm{O}}$ & $-40 \mathrm{~m}$
\end{tabular}

(Albertson 1996; Albertson and Parlange 1999a,b). Further details on the coupling of the LES model to the TSEB model can be found in Albertson et al. (2001), and a detailed description of the simulation settings can be found in Bertoldi et al. (2007, 2008).

The upper boundary condition is one of no vertical flow imposed well above the ABL capping inversion. Lateral boundary conditions are periodic, and the turbulent structure of the $\mathrm{ABL}$ is driven by a streamwise pressure gradient in the mean wind direction. The bottom boundary fluxes are estimated by the TSEB model, forced by the instantaneous near-surface atmospheric fields provided by LES (e.g. air temperature $T_{\mathrm{a}}$, specific humidity $q$, and wind speed $U$ ), by the averaged shortwave radiation $\left(R_{\mathrm{SW}}\right)$ from four weather stations inside the simulation domain, and by the remotely sensed $T_{\mathrm{S}}$, assumed to vary linearly in time between the two available radiometric surface temperature images, taken at 0630 CST and 1015 CST with an airborne thermal infrared multispectral scanner. The net longwave radiation balance has been calculated as described in Kustas and Norman (1999), where a single exponential equation has been used for estimating the transmission for both the soil and canopy, using canopy temperature, soil temperature, shelter level air temperature and vapour pressure as input.

The mixed-layer $U, q, T_{\mathrm{a}}$, and the lapse rate $\gamma$ in the inversion layer were taken from the 0845 CST sounding and used to initialize the general mean vertical structure of the model simulation. The simulated evolution of the mixed layer agrees well with sounding observations taken at 0945 CST and 1055 CST (Bertoldi et al. 2007). The model was run for a spin-up period, during which the turbulence of the simulated ABL became fully developed and the flow field reached a dynamic equilibrium with the underlying boundary conditions. Following the spin-up period was an averaging period of $1 \mathrm{~h}$. For analysis purposes, surface fluxes and flow field variables from LES have been time-averaged over this period. The LES grid cell size is $48 \mathrm{~m}$ in the horizontal direction and $5 \mathrm{~m}$ in the vertical. The main simulation settings and atmospheric properties are listed in Table 1.

\subsection{Aircraft and LES Flux Calculations}

Since the aircraft overpass times are not separated by a constant time interval, the aircraftderived fluxes considered in this analysis were computed as the temporal average of all 
aircraft overpasses, where the single tracks are weighted over the corresponding time intervals in a manner that gives greater weights to overpasses having longer time intervals. The fluxes for each overpass were calculated as a spatial average of the measurements from the aircraft, which are assumed to be at the same point in time. The LES-derived turbulent fluxes $H$ and $L E$ were calculated as local temporal averages over $1 \mathrm{~h}$ for every grid cell in $x, y, z$. The choice to time average LES results is justified by the necessity to have robust turbulent statistics, because the LES has a much coarser spatial resolution than the aircraft sampling. Both the resolved and the subgrid-scale flux components from the LES were considered. At the aircraft altitude ( $32 \mathrm{~m}$ above the ground) we found that more than $80 \%$ of the flux was resolved by the LES.

Only the turbulent flux components from the LES have been considered and the mean transport $(\langle w\rangle\langle\theta\rangle,\langle w\rangle\langle q\rangle)$ was not included in order to have LES-derived fluxes comparable with the aircraft measurements, which take into account only the contributions from the turbulent transport. This is because the aircraft measurement strategy and subsequent processing of the data results in small net vertical velocities, hence relatively small mean fluxes (Mahrt et al. 2001). However, the mean transport is taken into account in calculating the scalar fields $\langle q\rangle$ and $\langle\theta\rangle$ from the LES, which are considered reliable, and are analyzed and discussed below.

\section{Results}

In this section, the LES-derived fluxes are compared with surface observations and aircraftderived fluxes. Then, differences in the upwind source area between $H$ and $L E$ and the implications for flux-footprint modelling are discussed.

\subsection{Surface Fluxes}

The temporal evolution of observed surface values of $H$ and $L E$, averaged over four flux towers (positions indicated in Fig. 1a), agrees closely with the corresponding LES-based fluxes (averaged over the four grid cells in the lowest layer corresponding to the tower locations), as shown in Fig. 2. A more detailed comparison for each tower separately for the same case study is shown in Fig. 3 of Bertoldi et al. (2008). One can conclude from this comparison that the LES satisfactorily reproduces the magnitude and the temporal evolution of the surface fluxes. For a more detailed discussion on the spatial patterns of the surface fluxes and scalar fields, see Bertoldi et al. (2007).

\subsection{Aircraft Altitude Fluxes}

The magnitude of the LES-based fluxes at flight altitude (averaged over the length of the transect and represented as a bracketed quantity \langle\rangle ) agrees well with the aircraft measurements. For $\langle H\rangle$, both aircraft measurements and LES results yield $74 \mathrm{~W} \mathrm{~m}^{-2}$ while for $\langle L E\rangle$ the values are 320 and $335 \mathrm{~W} \mathrm{~m}^{-2}$, respectively. The close agreement in both LES-based $H$ and $L E$ with surface and aircraft-based observations suggests that the LES model can accurately reproduce the observed spatially-averaged $H$ and $L E$ at the land surface and higher in the atmospheric surface layer.

A comparison of the aircraft observations with LES, averaged over the 21 grid cells corresponding to the $1 \mathrm{~km}$ aircraft transect segments, is illustrated in Fig. 3. Here we focus on the 1018 CST aircraft overpass, since it is centred within the LES simulation time (from 


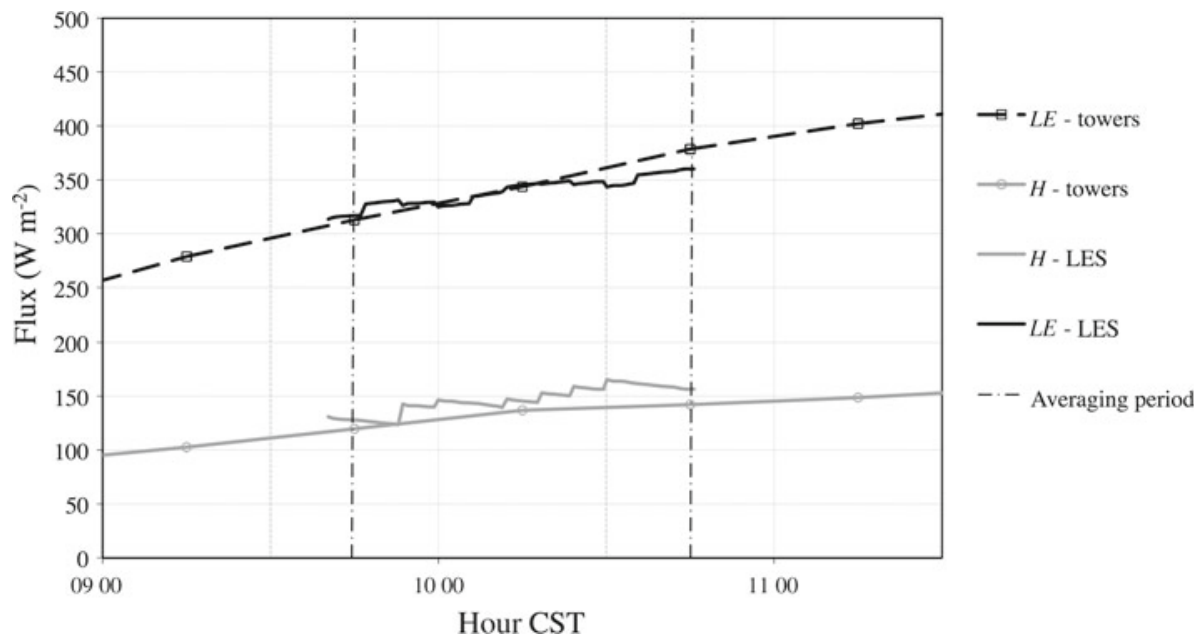

Fig. 2 Comparison of the observed and simulated surface $H$ and $L E$ temporal evolution. Observed fluxes are averaged over the four towers in the study area. Fluxes computed by LES are averaged over the four lowest layer grid cells corresponding to the towers locations
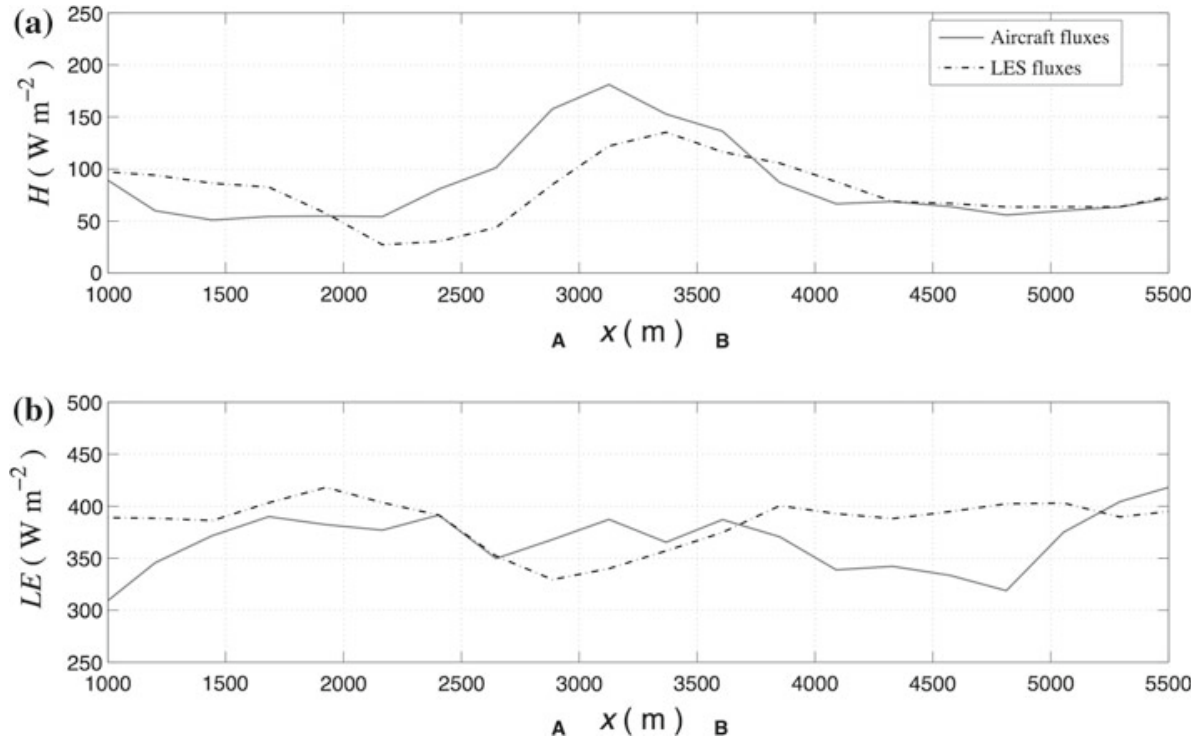

Fig. 3 Comparison of the spatial patterns of $H$ (a) and $L E$ (b) obtained from the aircraft observations and computed from LES, averaged for the same $1,000 \mathrm{~m}$ segments. The letters $A$ and $B$ indicate the position of the bare soil field/wheat stubble shown in Fig. 1. The first $1 \mathrm{~km}$ segment of the transect has been excluded from the comparison, because LES results are still affected by the periodic boundary conditions 
0945 CST to 1045 CST). The first $1000 \mathrm{~m}$ segment of the aircraft transect was excluded from the comparison, because LES results are still affected by the periodic boundary conditions and hence cannot provide reliable fluxes near the boundary. Moreover, aircraft observations were affected by a large, dry non-vegetated area upwind and outside of the LES modelling domain (see Kustas et al. 2006). As illustrated in Fig. 3, LES results show that $H$ increases in correspondence with the two "hot spots" A and B by an amount comparable to the increase in the aircraft observations $\left(\approx 130 \mathrm{~W} \mathrm{~m}^{-2}\right)$, such that both modelled and measured fluxes yield a similar peak along the transect. The LES predicts a slight decrease in $L E\left(\approx 70 \mathrm{~W} \mathrm{~m}^{-2}\right)$ over A and B, which is not observed in the aircraft fluxes. However, both the aircraft results and the LES model simulations indicate a more homogeneous pattern for $L E$ compared with that of $H$. This is confirmed by the other aircraft overpasses, as shown in Mahrt et al. (2001). While the increase in $H$ over A and B is consistent for every overpass, $L E$ shows a different spatial structure for every overpass.

This difference in spatial pattern/structure in $H$ versus $L E$ is compelling and motivates a more detailed analysis of the LES results in order to understand why small-scale surface heat sources tend to have a persistent effect on aircraft-altitude $H$, but a much less organized effect on $L E$, as previously found also by Samuelsson and Tjernstrom (1999). The answer would have implications for developing a flux source-area model that can handle aircraft and tall tower measurements over heterogeneous landscapes.

\subsection{Spatial Distribution of the Modelled Fluxes and Scalars}

A three-dimensional view of the near-surface LES-based $H$ and $L E$ fields is shown in Fig. 4. In correspondence with the surface heterogeneities (e.g. Fig. 4, locations A and B) $H$ and $L E$ are anti-correlated at the surface, because the energy balance constraint. However, at the flight altitude $(32 \mathrm{~m})$ an increase in $H$ along the flow path has no corresponding discernible decrease in $L E$ (actually a slight increase), weakening the correlation between $H$ and $L E$. This does not happen over a larger area of strong surface heating further upwind (Fig. 4, location $\mathrm{C}$ ), where $H$ and $L E$ remain anti-correlated well above the aircraft altitude. One possible explanation for this phenomenon to exist well into the mixed layer is that the height at which $H$ and $L E$ do not exhibit surface-layer behaviour and become positively correlated could depend on the spatial scale of the surface discontinuity.

From the results illustrated in Fig. 4, the following conceptual interpretation of the aircraft observations can be formulated: small areas with high surface heating surrounded by a moist region (e.g. fields A and B) are able to generate a localized but strong increase in surface $H$, and decrease in $L E$. However, at the flight altitude, $H$ still responds to local soil moisture and vegetation, while $L E$ is already becoming decoupled from the surface, caused by updrafts that facilitate convergence of surrounding water vapour. Therefore, at the aircraft altitude, $H$ shows a better correspondence with the underlying surface patterns in soil moisture and vegetation cover than does $L E$.

A possible interpretation of what is observed is that, at flight altitude, the correlation between $H$ and $L E$ can be both negative, which is associated with surface-layer transport processes, or positive, which is associated with mixed-layer dynamics. What determines the behaviour of $H$ and $L E$ with altitude relates to the spatial scale and the magnitude of the discontinuities in surface states (primarily soil moisture and vegetation cover), affecting the relative magnitudes of $H$ and $L E$. A schematic of the hypothetical behaviour of the surface fluxes in areas A and B is shown in Fig. 5. The schematic suggests that the localized updraft areas, created by the hot buoyant plumes, draw in water vapour from the surroundings, which tends to decouple $L E$ at flight altitude from local surface conditions and hence to weaken the 


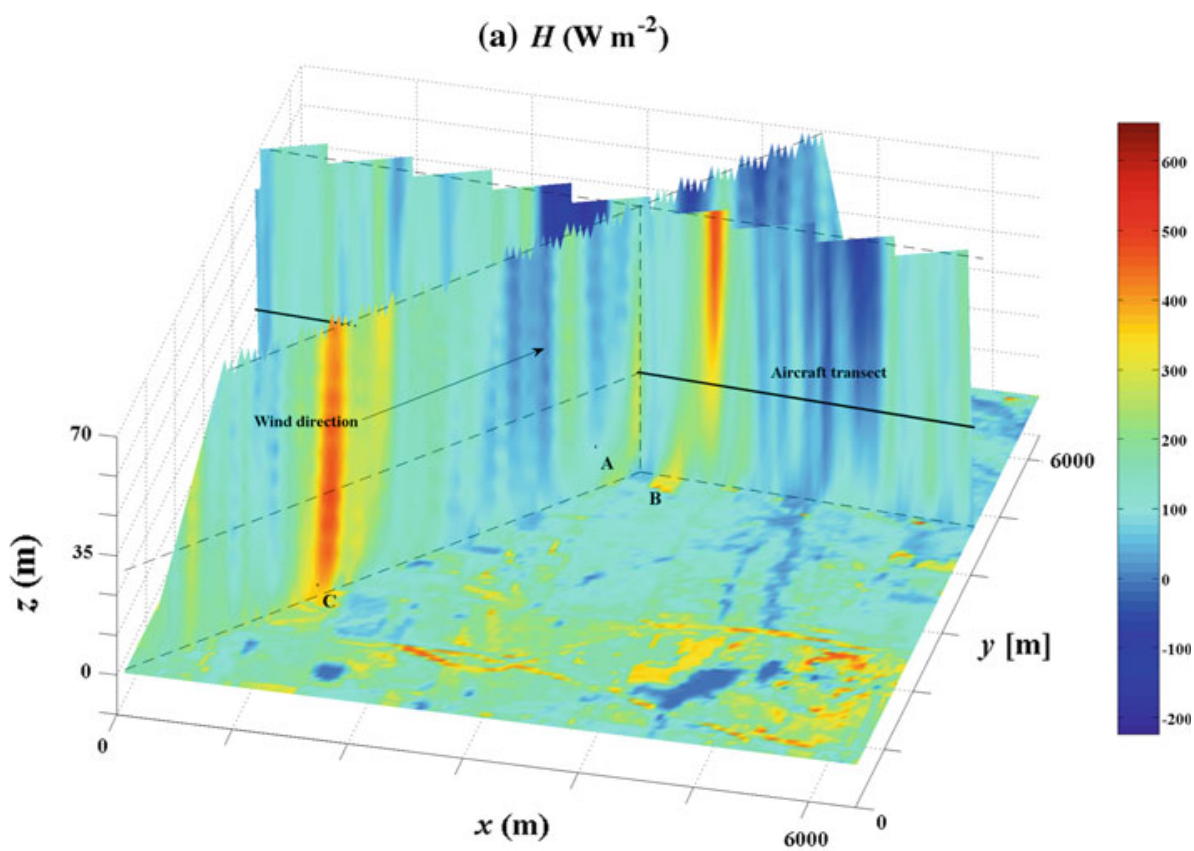

(b) $L E\left(\mathrm{~W} \mathrm{~m}^{-2}\right)$

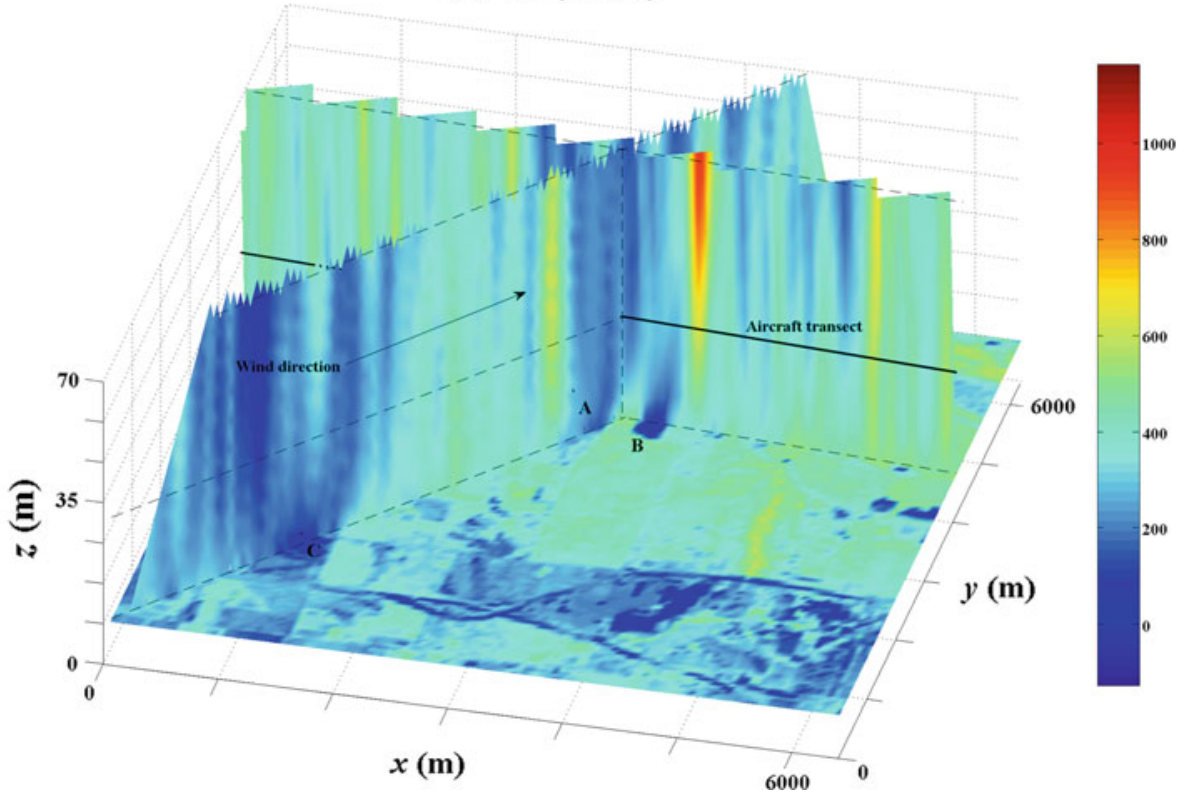

Fig. 4 Three-dimensional view of the simulated $H(\mathbf{a})$ and $L E$ (b) fields, with one horizontal slice at the surface, and two vertical slices (from the surface up to $z=72.5 \mathrm{~m} ; z /(\Delta z)=15$ ). The first is along the aircraft transect (bold black line) in correspondence of the bare soil/wheat stubble fields " $A$ " and " $B$ ". The second is along the wind direction, in correspondence of the larger bare soil/wheat stubble field " $C$ " 


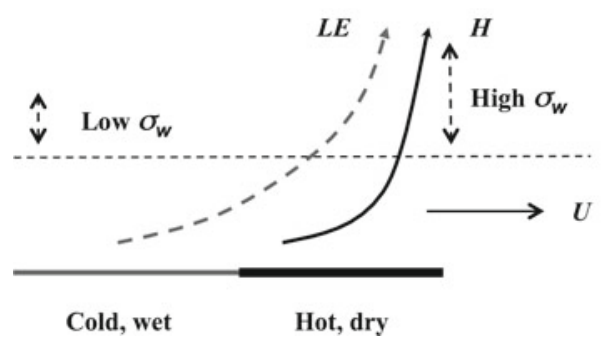

Mixed layer: $\rho_{H, L E}>\mathbf{0}$

$+H^{\prime},+L E^{\prime}$

\section{Aircraft elevation}

Ground surface : $\rho_{H, L E}<0 \quad+H^{\prime},-L E^{\prime}$

Fig. 5 Schematic of the hypothetical behaviour of the surface fluxes in correspondence to the "hot spot". $U$ is the mean horizontal wind speed; $\sigma_{\mathrm{W}}$ is temporal standard deviation in the vertical velocity. $H^{\prime}$ and $L E^{\prime}$ are the variations of sensible and latent heat fluxes with respect to their spatial average, and $\rho_{H, L E}$ is their spatial correlation

local surface energy balance constraint, which imposes a negative correlation between $H$ and $L E$. This interpretation of aircraft flux observations implies that water vapour is transported over longer horizontal distances than is the heat content $\left(\rho c_{\mathrm{p}} T\right)$ of air masses, as shown in Fig. 6, where it appears that $q$ is organized in rolls more elongated along the wind direction as compared to $\theta$. This is likely because the strong vertical mixing over warmer areas largely affects local temperature conditions. Although LeMone et al. (2003) already suggested that similar transport mechanisms cause decoupling of $H$ and $L E$ at aircraft altitudes, the authors are unaware of any prior studies using LES results that provide numerical evidence of this behaviour in the turbulent fluxes.

Here, we wish to verify quantitatively the conceptual scheme described above. For this reason, three simple quantities based on the LES results were considered, viz.:

1. As a metric for the tendency of the updrafts to enhance both $H$ and $L E$, the horizontal spatial correlation of the temporally averaged $H(x, y, z)$ and $L E(x, y, z)$ fields as a function of the altitude $z$, represented by $\rho_{H, L E}(z)$. We expect a change in the sign of this correlation with altitude.

2. As a measure of significance in horizontal transport, the horizontal shift or lag, $L(z)$, at which the scalar or the corresponding flux field should be shifted in order to maximize the correlation between their values at height $z$ and their surface distribution, i.e. $L_{H, H o}(z), L_{L E, L E o}(z), L_{\theta, \theta o}(z)$ and $L_{q, q o}(z)$. We expect greater magnitudes in $L(z)$ for water vapour than for temperature.

3. As an indicator of strong vertical mixing over warmer areas, the horizontal distribution of the standard deviation of vertical velocity at the aircraft altitude, represented by $\sigma_{\mathrm{w}}$.

\subsection{Spatial Correlation of $H$ and $L E$}

The correlation $\rho_{H, L E}(z)$ is a measure of the similarity in the spatial structure of the $H$ and $L E$ fields as a function of altitude. If $\rho_{H, L E}(z)<0$ and close to -1 , the fluxes reflect the partitioning effects of the surface energy balance constraint. If $\rho_{H, L E}(z) \approx 0$, then $H$ and $L E$ have been contrastingly affected by ABL dynamics, which include mixed-layer and $\mathrm{ABL}$ entrainment processes and no longer reflect the local surface energy balance. In cases where $\rho_{H, L E}(z)>0$, this indicates a convergence of water vapour and air temperature in the updrafts, and thus a correlation induced as the active scalar (temperature) drives the transport of the passive scalar (humidity).

In Fig. 7, the simulated $H$ and $L E$ are plotted for three horizontal cross-sections in proximity of the aircraft transect, near the surface $(z=2.5 \mathrm{~m}$, line $1-1)$, at the aircraft altitude 
(a) $\theta\left({ }^{0} \mathrm{C}\right)$

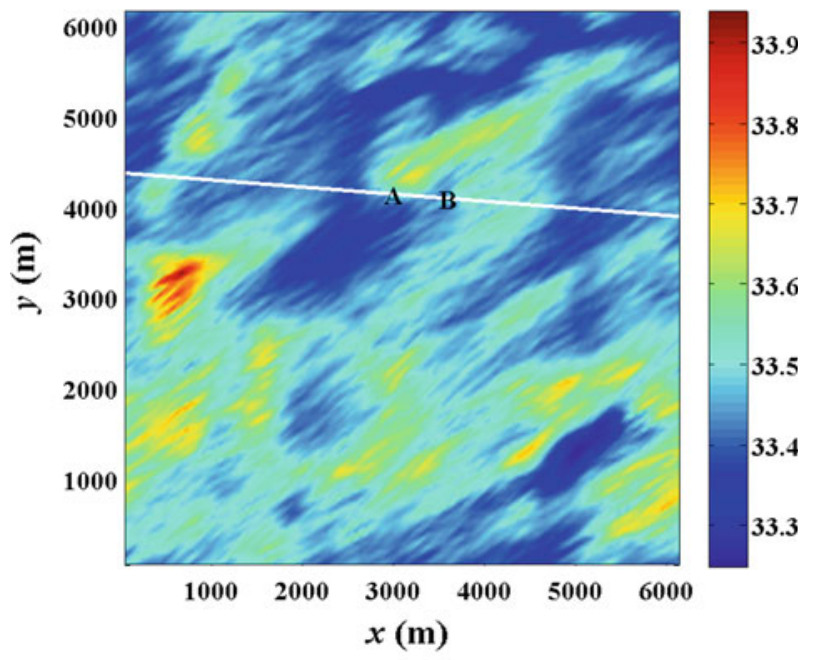

(b) $q(\mathrm{~g} / \mathrm{kg})$

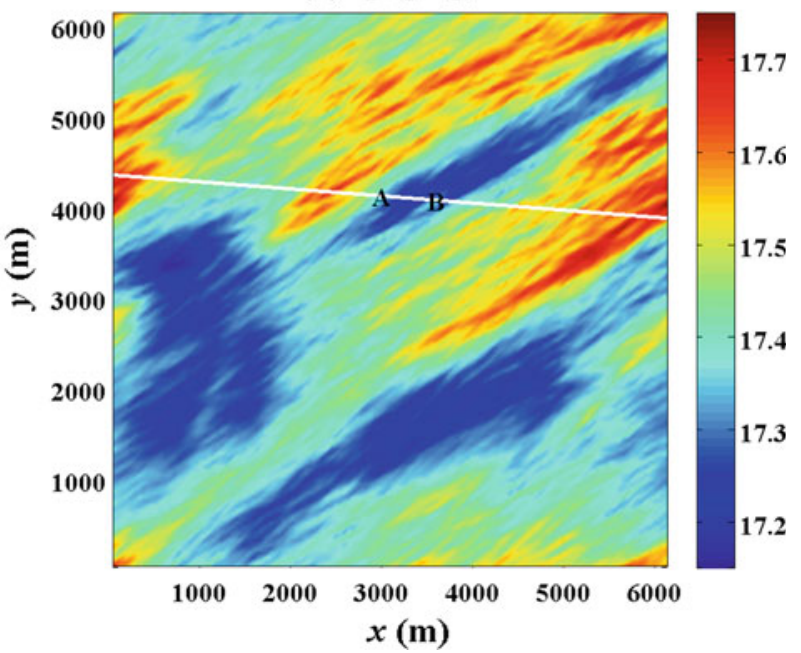

Fig. 6 Simulated spatial distribution of potential temperature $\theta(x, y)$ (a) and specific humidity $q(x, y)(\mathbf{b})$ for the aircraft transect altitude $(z=32 \mathrm{~m})$

$(z=32 \mathrm{~m}$, line 2-2), and in the mixed layer $(z=102.5 \mathrm{~m}$, line 3-3). The cross-section for line (1-1) contains no downwind shift from the ground pixels where bare soil fields " $\mathrm{A}$ " and "B" are denoted, while lines (2-2) and (3-3) are shifted by 340 and 1,300 $\mathrm{m}$ downwind, respectively, as indicated in the schematic in Fig. 7. For a given altitude, a downwind shift was needed in order to capture the maximum effect of the surface discontinuities on the transects $H$ and $L E$. The magnitude of this shift was estimated by calculating the location/distance upwind where the maximum source flux contribution originated, using the Schuepp et al. (1990) footprint model. Key inputs were the spatially-averaged horizontal wind speed at the 
Section 3-3; $z=102.5 \mathrm{~m} ; \rho_{H, L E}(z)_{48}=0.29 ; \rho_{H, L E}(z)_{1000}=0.25$

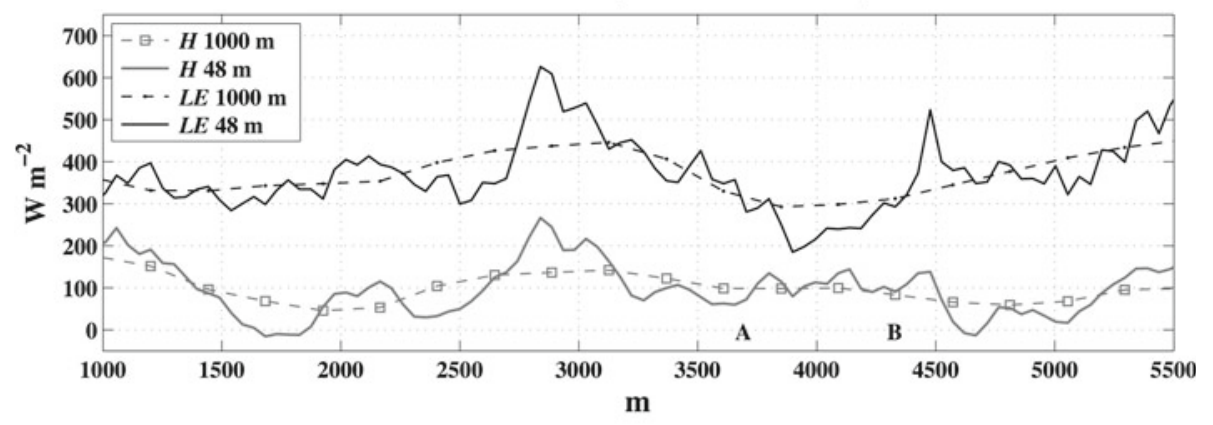

Section 2-2; $z=32.5 \mathrm{~m} ; \rho_{H, L E}(z){ }_{48}=-0.38 ; \rho_{H, L E}(z){ }_{1000}=-0.9$

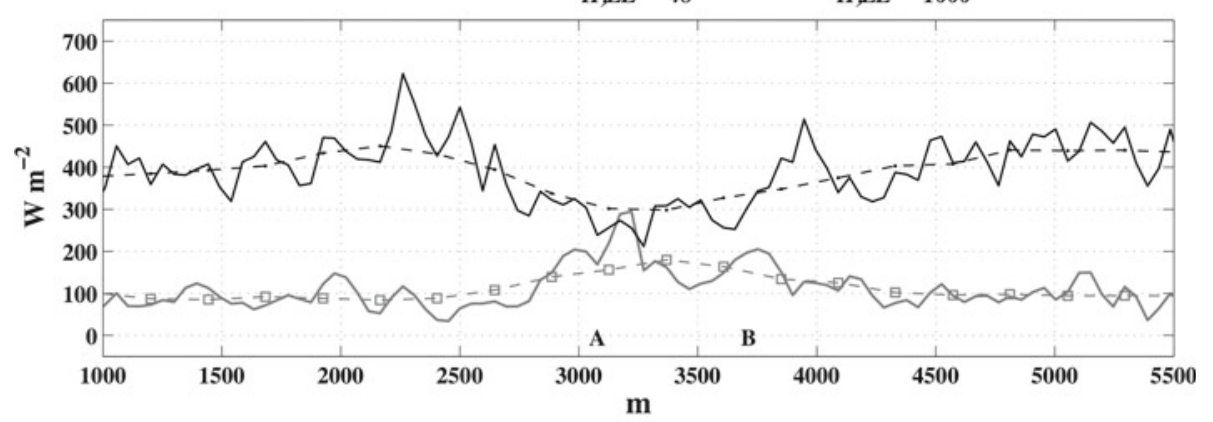

Section 1 $1 ; z=2.5 \mathrm{~m} ; \rho_{H, L E}(z){ }_{48}=-0.93 ; \rho_{H, L E}(z){ }_{1000}=-0.98$
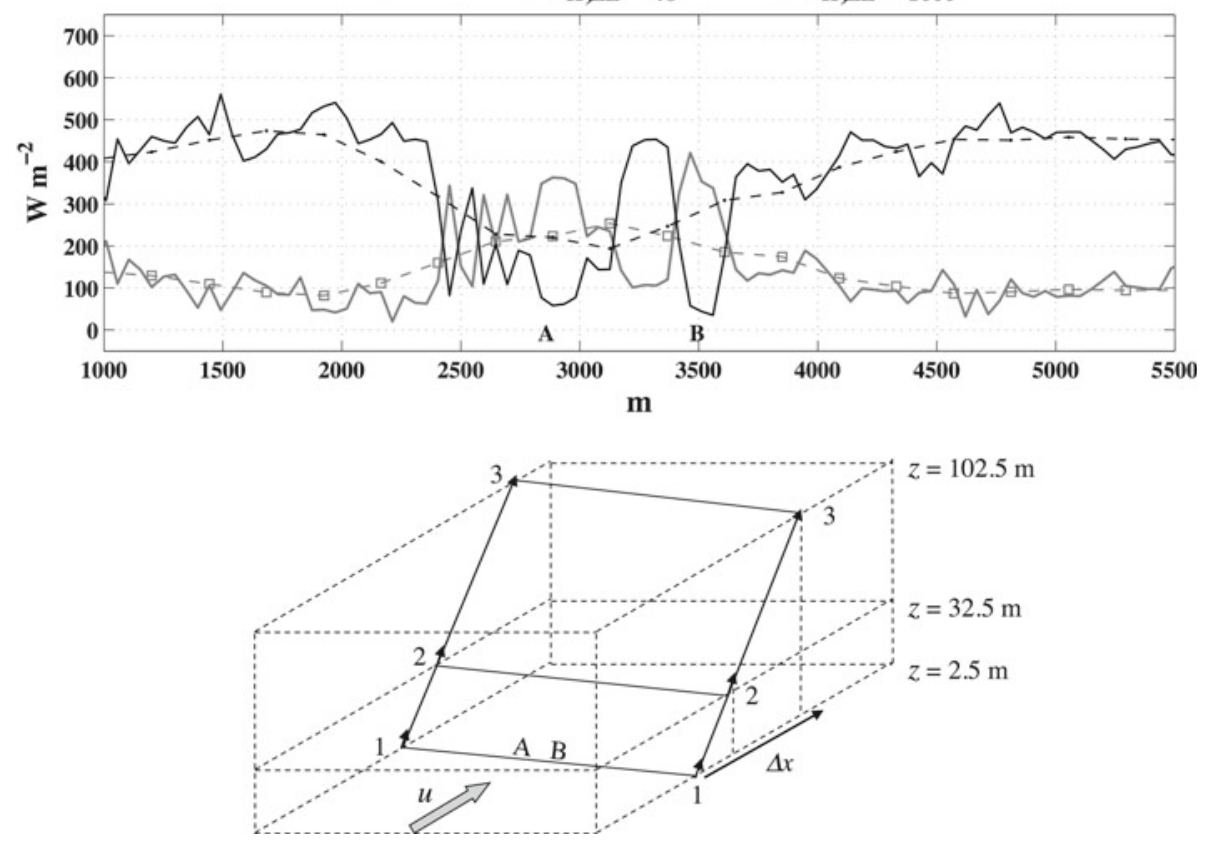
Fig. 7 Simulated $H$ and $L E\left(\mathrm{~W} \mathrm{~m}^{-2}\right)$ for the grid cells comprising three different height levels. The scheme below indicates the position of the sections/lines (1-1), (2-2), and (3-3) inside the LES simulation domain. Line (1-1) is at the surface level in proximity of the bare soil fields " $A$ " and " $B$ "; line (2-2) is at the aircraft altitude $(z=32 \mathrm{~m})$ shifted down-wind $(\Delta x=340 \mathrm{~m})$; line $(3-3)$ is in the mixed layer $(z=102 \mathrm{~m}$, $\Delta x=1,300 \mathrm{~m})$. In the plots $H$ and $L E$ and the spatial correlations $\rho_{H, L E}(z)_{48}$, at grid resolution, and $\rho_{H, L E}(z)_{1000}$, averaged over $1,000 \mathrm{~m}$ segments, are reported. The positions of the letters " $A$ " and " $B$ " along the $x$ axis indicate the likely maximum contributions along the transect of the fluxes coming from the bare soil fields " $A$ " and " $B$ " of Fig. 1. The position is shifted downwind with increasing altitude

corresponding model altitude and an estimate of $u_{*}\left(=0.38 \mathrm{~m} \mathrm{~s}^{-1}\right)$. For details see Kustas et al. (2006).

In Fig. 7, the longitudinal profiles of $H$ and $L E$ for the grid cells along lines 1-1,2-2 and 3-3 are illustrated. In addition, $\rho_{H, L E}(z)$ is calculated at the original grid resolution of $48 \mathrm{~m}$ $\left(\rho_{H, L E}(z)_{48}\right)$ and averaged over $1,000 \mathrm{~m}$ segments $\left(\rho_{H, L E}(z)_{1000}\right)$, in order to have a spatial resolution comparable with the aircraft observations. As expected, $\rho_{H, L E}(z)$ is dependent on both the altitude and the grid resolution.

At the surface (line 1-1), $H$ and $L E$ conform to the energy balance constraint where $\rho_{H, L E}(z) \approx-1$ at both the 48 - and 1,000 -m spatial scales, $\left(\rho_{H, L E}(z)_{48}=-0.93\right.$ and $\left.\rho_{H, L E}(z)_{1000}=-0.98\right)$. At $z=32 \mathrm{~m}$ (line $2-2$ at the aircraft transect altitude), the negative correlation is weaker at the smaller grid size, but still strong at the $1,000 \mathrm{~m}$ resolution $\left(\rho_{H, L E}(z)_{48}=-0.38\right.$ and $\left.\rho_{H, L E}(z)_{1000}=-0.90\right)$, consistent with the concept illustrated in Fig. 5. If the entire horizontal modelling domain of the LES at $z=32 \mathrm{~m}$ is considered, and not just a single transect (line 2-2), the overall correlation $\rho_{H, L E}(z)_{1000}=-0.62$ is closer to the correlation computed with the aircraft observations $\left(\rho_{H, L E}(z)=-0.41\right)$ at $1,000 \mathrm{~m}$ resolution along the transect. At $102 \mathrm{~m}$ (line 3-3, in the mixed layer), $H$ and $L E$ show a positive correlation at both resolutions $\left(\rho_{H, L E}(z)_{48}=0.29\right.$ and $\left.\rho_{H, L E}(z)_{1000}=0.25\right)$. This suggests that mixed-layer and entrainment processes were significantly affecting heat and water vapour transport at this altitude in the ABL.

The change in the overall pattern of the $H$ and $L E$ profiles illustrated in Fig. 7 for lines $1-1,2-2$ and to $3-3$ indicates that, with increasing altitude, the major peaks in the $L E$ profile tend to shift into phase with those of the $H$ profile. Based on the conceptual model described in Fig. 5, this implies that locally generated buoyant plumes dominate water vapour transport in the mixed layer, which entrains more humid air from the surrounding wetter areas in the landscape. At the higher altitude, this causes the correlation between $H$ and $L E$ to be decoupled from the energy balance constraint imposed at the surface. However, at the aircraft altitude, fluxes still reflect to some degree surface-layer $H$ and $L E$ partitioning at larger spatial scales, as evident in the persistence of $\rho_{H, L E}(z)<0$ computed from the aircraft measurements. The different patterns in $H$ and $L E$ with altitude generated by the LES (Fig. 7) reflect this scale-dependent transition between two different turbulent regimes, namely the surface layer and the mixed-layer/ABL entrainment. This process changes the correlation between $H$ and $L E$ from $\rho_{H, L E}(z)<0$ (surface-layer turbulence/local energy conservation) to $\rho_{H, L E}(z)>0$ (mixed-layer turbulence/ABL transport).

\subsection{Horizontal Transport of Water Vapour and Temperature}

To examine whether water vapour is being transported for longer horizontal distances than heat we focus on the distance $L(z)$ at which the scalar or the corresponding flux field should be shifted in order to maximize the correlation between their values at height $z$ and their surface distribution. In Fig. 8 this lag/distance and the value of the maximum correlation (at 

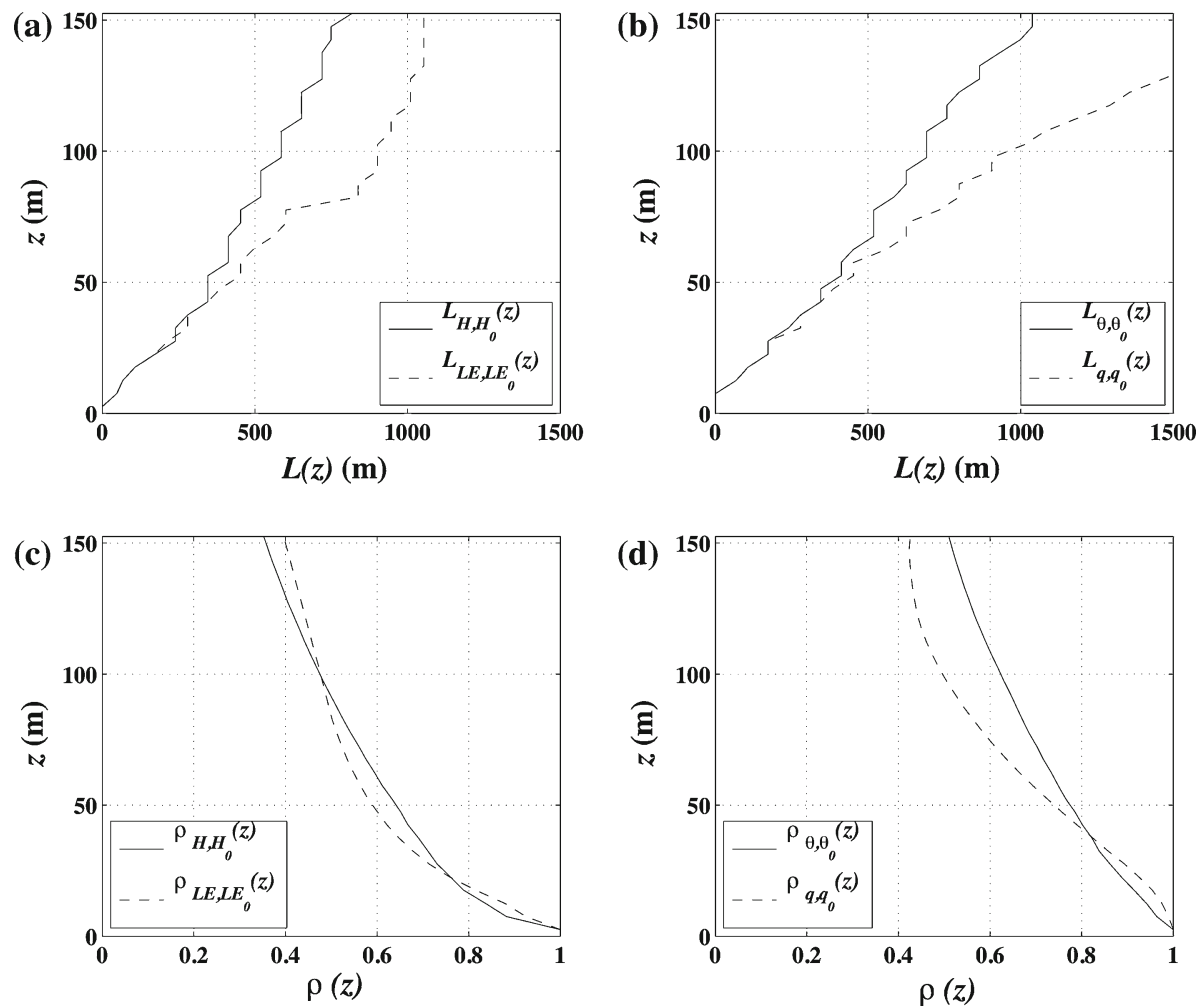

Fig. 8 The horizontal distance $L(z)$ at which the scalar and corresponding flux fields need to be shifted in order to maximize the correlation $\rho$ with their surface distributions, as function of the altitude $z$. a $L_{H, H o}(z)$ and $L_{L E, L E o}(z)$ for $H$ and $L E ; \mathbf{b} L_{\theta, \theta o}(z)$ and $L_{q, q o}(z)$ for the $\theta$ and $q$; $\mathbf{c}$ the maximum correlations at the shift distance $L(z)$ for $H$ and $L E, \rho_{H, H o}(z)$ and $\rho_{L E, L E o}(z)$ respectively; $\mathbf{d}$ the maximum correlations at the shift distance $L(z)$ for $\theta$ and $q, \rho_{\theta, \theta o}(z)$ and $\rho_{q, q o}(z)$, respectively

this lag) have been calculated for $H, L E, \theta$ and $q$, considering all the cells at height $z$ in the study area. Above the surface layer, $q$ and $L E$ show greater horizontal lags than those seen for $\theta$ and $H$ (Fig. 8a and b). This confirms the conceptual scheme illustrated in Fig. 5. The corresponding vertical profiles of the maximum correlation (Fig. 8c and d) show, as expected, a decrease in the correlation strength with altitude for all quantities, and, interestingly, a more rapid decrease in $q$ with respect to $\theta$. However, the fact that $L(z)$ values between $H$ and $L E$ are similar at aircraft altitude $(\approx 32 \mathrm{~m})$ suggests that differences in source-area contributions are likely to appear under conditions where the magnitude and scale of contrasts in surface heat and soil moisture conditions with the surrounding region have certain properties/characteristics that enable different heat content and water vapour transport dynamics to propagate into the surface layer. This is observed in Fig. 4, where, at location $\mathrm{C}, \rho_{H, L E}(z)$ remains negative ( $\mathrm{H}$ increases where $\mathrm{LE}$ decreases) above the aircraft altitude and into the mixed layer, in contrast to areas $\mathrm{A}$ and $\mathrm{B}$ where $\rho_{H, L E}(z)$ is changing sign. Clearly there is a difference in the size and degree of contrast between the hot/dry discontinuity and the surrounding well-watered vegetated area that plays a role in the behaviour of $\rho_{H, L E}(z)$. 
(a) $\sigma(w)\left(\mathrm{m} \mathrm{s}^{-1}\right)$

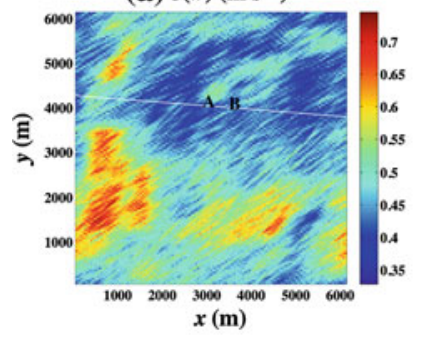

(b)

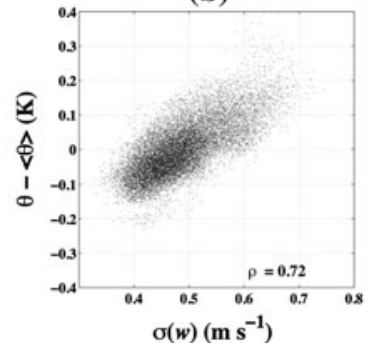

(c)

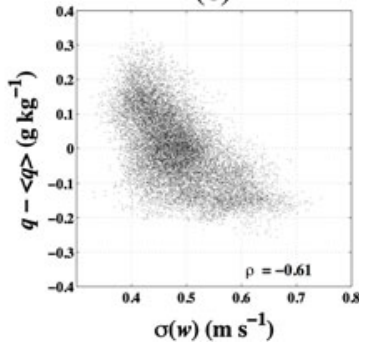

Fig. 9 a Spatial distribution of the temporal standard deviation of the vertical velocity, $\sigma_{\mathrm{w}}$, at the aircraft transect altitude $(z=32 \mathrm{~m})$; b scatter-plot of $\sigma_{\mathrm{W}}$ against the time-averaged deviation of the potential temperature from its spatial mean $\theta-\langle\theta\rangle ; \mathbf{c} \sigma_{\mathrm{W}}$ against specific humidity deviation $q-\langle q\rangle$

\subsection{Strength of the Vertical Mixing and Implications for Footprint Estimation}

The difference in horizontal transport of water vapour and temperature above the surface layer can be related to the differences in the intensity of vertical mixing over warm and cold patches. The standard deviation of the vertical velocity $\sigma_{\mathrm{w}}$ is a simple measure of the intensity of the vertical turbulent mixing. Larger values of $\sigma_{\mathrm{w}}$ imply a stronger vertical scalar dispersion, and therefore the flux-footprint distribution estimated using a simplified flux-footprint model (i.e., Schuepp et al. 1990) would have the peak source-area contribution closer to the flux sensor.

In Fig. 9, a map of the spatial distribution of $\sigma_{\mathrm{w}}$ over the modelling domain at the aircraft transect altitude illustrates how $\sigma_{\mathrm{w}}$ is positively correlated with the time-averaged temperature $\theta$ (Fig. 9b), and negatively correlated with $q$ (Fig. 9c). This result comes from the fact that the magnitude of $\sigma_{\mathrm{w}}$ is strongly related to the underlying $\mathrm{H}$ distribution. Consequently, over wet areas there is greater $q$ production, but lower values of $\sigma_{\mathrm{w}}$, while over dry areas $\theta$ is higher and $\sigma_{\mathrm{w}}$ is also greater: this leads to a stronger vertical mixing of $\theta$, and to a weaker vertical mixing of $q$. With a less efficient vertical transport of $q$ compared to $\theta$ in the surface layer, this results in greater horizontal transport of $q$ relative to $\theta$. An important implication of these findings is that the use of flux-footprint models assuming similarity in the transport of water vapour and heat may not be appropriate under certain atmospheric conditions (e.g., strongly convective conditions in locations with significant contrasts in surface soil moisture and temperature).

\section{Conclusions}

In this paper we have illustrated the physical factors that are likely to create significant differences in the upwind source area contributing to $H$ and $L E$ measurements made from an aircraft near the top of the surface layer. Both observational and modelling results using LES over a real landscape are used to determine the key surface and atmospheric processes contributing to this disparity in source-area flux contributions from an active scalar (air temperature) and a passive scalar (water vapour).

Flux-aircraft observations from SGP97, together with surface-flux fields generated from a remote sensing based land-surface model provided evidence of a difference in the source-area contributions to $H$ and $L E$ (Kustas et al. 2006). This provided the impetus for the current investigation, which considered the hypothesis that a key physical process underlying this 
phenomenon is an increase in the vertical velocity variance coupled with increased air temperature over the arid patches, resulting in a localized increase in turbulent sensible heat flux, identified earlier by Lenschow et al. (1980) and Young (1988) for similar conditions.

A LES, with remotely sensed boundary conditions, was used to realistically simulate the land-atmosphere dynamics. The LES was able to accurately estimate the observed magnitude of $H$ and $L E$, both at the surface and at the aircraft altitude. In particular, aircraft observations over a hot, dry, bare field along the transect showed a strong localized increase in $H$, with no corresponding decrease in the aircraft-derived $L E$, as would be observed at the surface based on energy balance principles. The LES was able to simulate a similar behaviour over the same area.

LES results indicated that relatively small areas or patches containing dry bare soil/senescent vegetation with associated high surface temperatures, surrounded by unstressed dense vegetation with significantly lower surface temperatures, are able to generate strong, but localized, sensible heating, with an increase in $H$ and a decrease in $L E\left(\rho_{H, L E}(z)<0\right)$. However, at the aircraft altitude $(\approx 30 \mathrm{~m})$, whereas $H$ still reflects the surface heating patterns, $L E$ remains high due to strong updrafts related to the convergence of surrounding air with higher specific humidity. This forces an increase in $\rho_{H, L E}(z)$ from its value of nearly -1 at the surface to positive values above the surface layer.

LES results show an increase in the specific humidity $q$ and a decrease in $\sigma_{\mathrm{w}}$ over the wet/densely vegetated areas, while over areas with dry soils and senescent vegetation both $\theta$ and $\sigma_{\mathrm{w}}$ are increased. This leads to a stronger vertical mixing of $\theta$, and to a weaker vertical mixing of $q$, resulting in a greater horizontal transport of $q$ under the same synoptic windfield conditions. Consequently, the simulated $q$ and $L E$ fields require a larger horizontal shift (lag) than do $\theta$ and $H$ in order to maximize the correlation with their surface distributions. This finding is consistent with the results of Kustas et al. (2006), who found the flux footprint for $H$ to be much closer to the aircraft flight track than for $L E$.

These results also raise a concern over the assumption typically used in flux-footprint models that $\sigma_{\mathrm{w}}$ is horizontally homogeneous over the landscape. The LES, however, computes a $\sigma_{\mathrm{w}}$ field having significant spatial variability over the modelling domain. This suggests a need to develop flux-footprint models that consider differing source-area contributions between active $(H)$ and passive $(L E)$ scalar fluxes. This is of greater necessity when applied to aircraft flux observations made at upper levels in the atmospheric surface layer and/or mixed layer.

Acknowledgments This work was supported by NASA grant NAG13-99008: "Accounting for Effects of Sub-pixel Surface Variability on Regional Flux Estimation Using Large Eddy Simulation with Terra and Aqua Sensors" and by the grant "HydroAlp" and the incoming researchers project "Climaveg" of the "Ripartizione Diritto allo Studio, Universitá e Ricerca Scientifica" of the "Provincia Autonoma di Bolzano_Alto Adige" (Italy). We thank M. Cassiani and G. Bohrer of Duke University for their useful suggestions on data analysis techniques.

Disclaimer The U.S. Department of Agriculture (USDA) prohibits discrimination in all its programs and activities on the basis of race, colour, national origin, age, disability, and where applicable, sex, marital status, familial status, parental status, religion, sexual orientation, genetic information, political beliefs, reprisal, or because all or part of an individual's income is derived from any public assistance program. (Not all prohibited bases apply to all programs.) Persons with disabilities who require alternative means for communication of program information (Braille, large print, audiotape, etc.) should contact USDA's TARGET Center at (202) 720-2600 (voice and TDD). To file a complaint of discrimination, write to USDA, Director, Office of Civil Rights, 1400 Independence Avenue, S.W., Washington, D.C. 20250-9410, or call (800) 795-3272 (voice) or (202) 720-6382 (TDD). USDA is an equal opportunity provider and employer. 


\section{References}

Albertson JD (1996) Large eddy simulation of land-atmosphere interaction. Ph.D. thesis, University of California, Davis, $185 \mathrm{pp}$

Albertson JD, Parlange MB (1999a) Natural integration of scalar fluxes from complex terrain. Adv Water Resour 23:239-252

Albertson JD, Parlange MB (1999b) Surface length scales and shear stress: implications for land-atmosphere interaction over complex terrain. Water Resour Res 35:2121-2132

Albertson JD, Kustas WP, Scanlon TM (2001) Large-eddy simulation over heterogeneous terrain with remotely sensed land surface conditions. Water Resour Res 37:1939-1953

Asanuma J, Brutsaert W (1999) The effect of chessboard variability of the surface fluxes on the aggregated turbulence fields in a convective atmospheric surface layer. Boundary-Layer Meteorol 91:37-50

Bertoldi G, Albertson JD, Kustas WP, Li F, Anderson MC (2007) On the opposing roles of air temperature and wind speed variability in flux estimation from remotely sensed land surface states. Water Resour Res -W10433 . doi:10.1029/2007WR005911

Bertoldi G, Kustas WP, Albertson JD (2008) Estimating spatial variability in atmospheric properties over remotely sensed land-surface conditions. J Appl Meteorol 47:2147-2165. doi:10.1175/2007JAMC1828. 1

Cai XH, Leclerc MY (2007) Forward-in-time and backward-in-time dispersion in the convective boundary layer: the concentration footprint. Boundary-Layer Meteorol 123(2):201-218

Fleisch T (1996) The footprint for flux measurements, from backward Lagrangian stochastic models. Boundary-Layer Meteorol 78:399-404

French AN, Schmugge T, Kustas WP, Brubaker K, Prueger J (2003) Surface energy fluxes over El Reno, Oklahoma using high resolution remotely sensed data. Water Resour Res 39(6). doi:10.1029/2002WR1734

Garcia-Carreras L, Parker DJ, Marsham JH (2011) What is the mechanism for the modification of convective cloud distributions by land surface-induced flows?. J Atmos Sci 68:619-634. doi:10.1175/2010JAS3604. 1

Horst TW, Weil JC (1992) Footprint estimation for scalar flux measurements in the atmospheric surface-layer. Boundary-Layer Meteorol -3279296

Hsieh C, Katul G, Chi T (2000) An approximate analytical model for footprint estimation of scalar fluxes in thermally stratified atmospheric flows. Adv Water Resour 23:765-772

Huang HY, Margulis SA (2009) On the impact of surface heterogeneity on a realistic convective boundary layer. Water Resour Res 45:W04425. doi:10.1029/2008WR007175

Huang HY, Margulis SA, Chu CR, Tsai HC (2011) Investigation of the impacts of vegetation distribution and evaporative cooling on synthetic urban daytime climate using a coupled LES-LSM model. Hydrol Process 25:1574-1586. doi:10.1002/hyp.7919

Jackson TJ, LeVine DM, Hsu A, Oldak A, Starks P, Swift C, Isham J, Haken M (1999) Soil moisture mapping at regional scales using microwave radiometry: the Southern Great Plains Hydrology Experiment. IEEE Trans Geosci Remote Sens 37:2136-2151

Kaharabata SK, Shuepp PH, Ogunjemiyo S, Shen S, Leclerc MY, Desjardins RL, MacPherson JI (1997) Footprint considerations in BOREAS. J Geophys Res 102(D24):29113-29124

Kaharabata SK, Schuepp P, Fuentes J (1999) Source footprint considerations in the determination of volatile organic compound fluxes from forest canopies. J Appl Meteorol 38(7):878-884

Kelly RD, Smith EA, MacPherson JI (1992) A comparison of surface sensible and latent heat fluxes from aircraft and surface measurements in FIFE 1987. J Geophys Res 97(D17):18445-18453

Kljun N, Rotach MW, Schmid HP (2002) A three-dimensional backward lagrangian footprint model for a wide range of boundary-layer stratifications. Boundary-Layer Meteorol 103(3):205-226

Kustas WP, Albertson JD (2003) Effects of surface temperature contrast on land-atmosphere exchange: a case study from Monsoon90. Water Resour Res 39(6):1159. doi:10.1029/2001WR001226

Kustas WP, Norman JM (1999) Evaluation of soil and vegetation heat flux predictions using a simple twosource model with radiometric temperatures for partial canopy cover. Agric For Meteorol 94(1):13-29

Kustas WP, Anderson MC, French AN, Vickers D (2006) Using a remote sensing field experiment to investigate flux-footprint relations and flux sampling distributions for tower and aircraft-based observations. Adv Water Resour 29:355-368

Leclerc MY, Thurtell GW (1990) Footprint prediction of scalar fluxes using a Markovian analysis. Boundary-Layer Meteorol 52(3):247-258

Leclerc MY, Shen S, Lamb B (1997) Observations and large-eddy simulation modeling of footprints in the lower convective boundary layer. J Geophys Res 102(D8):9323-9334

LeMone MA, Grossman RL, Chen F, Ikeda K, Yates D (2003) Choosing the averaging interval for comparison of observed and modeled fluxes along aircraft transects over a heterogeneous surface. J Hydrometeorol 4:179-195 
LeMone MA, Chen F, Alfieri JG, Tewari M, Geerts B, Miao Q, Grossman RL, Coulter R (2007) Influence of land cover and soil moisture on the horizontal distribution of sensible and latent heat fluxes in southeast Kansas during IHOP-2002 and CASES-97. J Hydrometeorol 8:68-87

Lenschow DH (1970) Airplane measurements of planetary boundary layer structure. J Appl Meteorol 9:874884

Lenschow DH, Wyngaard JC, Pennel WT (1980) Mean-field and second-moment budgets in a baroclinic, convective boundary layer. J Atmos Sci 37:1313-1326

MacPherson JI (1998) Twin otter operations in the 1997 Southern Great Plains experiment. Institute for Aerospace Research Report LTR-FR-146, National Research Council Canada, 122 pp

Mahrt L, Vickers D, Sun J (2001) Spatial variations of surface moisture flux from aircraft data. Adv Water Resour 24:1133-1141

Norman JM, Kustas WP, Humes KS (1995) A two-source approach for estimating soil and vegetation energy fluxes from observations of directional radiometric surface temperature. Agric For Meteorol 77:263-293

Roth M, Oke T (1995) Relative efficiencies of turbulent transfer of heat, mass and momentum over a patchy urban surface. J Atmos Sci 52(11):1863-1874

Samuelsson P, Tjernstrom M (1999) Airborne flux measurements in NOPEX: comparison with footprint estimated surface heat fluxes. Agric For Meteorol 98(99):205-225

Schmid HP (2002) Footprint modeling for vegetation atmosphere exchange studies: a review and perspective. Agric For Meteorol 113(1-4):159-183

Schuepp P, Leclerc MY, MacPherson JI, Desjardins R (1990) Footprint prediction of scalar fluxes from analytical solutions of the diffusion equation. Boundary-Layer Meteorol 50:355-373

Sempreviva AM, Hojstrup J (1998) Transport of temperature and humidity variance and covariance in the marine surface layer. Boundary-Layer Meteorol 87:233-253

Twine TE, Kustas WP, Norman JM, Cook DR, Houser PR, Meyers TP, Prueger JH, Starks PJ, Wesely ML (2000) Correcting eddy-covariance flux underestimates over grassland. Agric For Meteorol 103:279_ 300

Young GS (1988) Turbulence structure of the convective boundary layer, Part I: variability of normalized turbulence statistics. J Atmos Sci 45:719-726 